\title{
Environmental Identity and Community Support for the Preservation of Open Space
}

\author{
Janet K. Swim, ${ }^{1}$ Stephanie J. Zawadzki, Jessica L. Cundiff, \\ and Bruce Lord \\ The Pennsylvania State University, United States
}

\section{Abstract}

The preservation of open space, preserved or minimally developed stretches of land, is a pressing issue facing many United States' communities. This paper examines one United States township's attempts to preserve open space. Most residents surveyed (96 percent) approved of preserving open space, and most homeowners (73 percent) were willing to pay increased property taxes for preservation. Strong identification with nature and the township were associated with willingness to pay higher taxes. Respondents also rated the importance of qualities afforded by preserving open space. Valuing qualities of open spaces related to preserving its present state (e.g., preserving ecology and historical places) and following already established plans mediated relations between residents' identification with nature and the township and their willingness to pay to preserve open space. Qualities that increase human access to the space (e.g., recreation and accessibility) did not show the same mediational relations. These results suggest that psychological identification with nature and the community play important roles in pro-environmental support. Both the practical and theoretical contributions of this research are discussed.

Keywords: applied research, environmental identity, open space, place identity, willingness to pay

\section{Introduction}

Open spaces are important for protecting the natural environment, for preserving a community's natural and social history, and for their psychologically restorative qualities. These spaces include undeveloped lands such as national parks or natural geological features in the form of special rock formations or waterfalls; moderately developed areas, such as agricultural lands and recreation areas in the form of parks and golf courses; and connections between spaces provided by walking and bicycle paths (Backlund et al., 2004; McDonald et al., 2010; USDA,

1 Corresponding author: jswim@psu.edu. 
2006). Open spaces can be privately or publicly owned and can be classified as either potentially developable or permanently protected from development (Irwin, 2002). Permanent preservation of open space allows it to remain in an undeveloped or relatively underdeveloped state. Preservation protects the ecosystems' land, water, flora, and fauna from destructive development, benefiting both the natural environment and community residents.

This paper reports on a rural Pennsylvania township's efforts to preserve open space and, in particular, the community members' support for preserving open space. Practically, the paper reports survey data about the qualities of space that residents deemed most important, their willingness to pay to preserve the space, and the use of the results by the community. Theoretically, the paper addresses the role of residents' environmental identity in support for preservation of open space and whether this relation can be explained by the qualities of open space residents deem important. We conclude with a discussion of the implications for community action research and practice and citizen participation in local government efforts to preserve their environments.

\section{Qualities of open space}

There is a long history of preserving open space in the United States, spanning the colonial period to the present day (Cordell et al., 1990; Jensen \& Guthrie 2006; Moore \& Driver 2005). Yet, open space is being threatened by population growth and distribution, and large-scale development that typically accompanies growth. Rural areas with increases in population are particularly prone to disproportionately large development because of the tendency toward low density and spatially sprawled development in these areas (USDA, 2006).

Rural areas are geographically close to natural resources, which means that the loss of open spaces in rural areas can be especially ecologically problematic (Geoghagen, 2002). For example, land development near forests makes forest management more difficult. Such development threatens water quality and wildlife habitats by fragmenting wildlife movement. Development in rural areas also increases threats to local biodiversity, reduces public recreation options, and reduces local economic resources, such as produce from local farms and timber from forests. In response to these threats, communities across the United States are attempting to preserve open space within their communities (Geoghagen, 2002; Kline, 2006; USDA, 2006).

Open spaces vary in their physical qualities (Backlund et al., 2004; McDonald et al., 2010; USDA, 2006). They vary in their level of development and their levels of human involvement in maintenance. Some open spaces are protected nature preserves. Others are areas that require more maintenance and are more 
specifically about addressing human needs, such as agricultural land for food and occupations, or pleasures, such as golf courses for recreation. Thus, open spaces afford different types of benefits to humans both in terms of direct use of the land and in terms of preserving biological diversity and ecological health.

Understanding what a community perceives to be important about open space is important for predicting whether or not the community will support local policies to protect these spaces (Banzhaf et al., 2010; Irwin, 2002). Some spaces may be valued because they provide residents with opportunities for recreation. Other spaces may be valued because of the particular historical value provided to the community, such as places where civil war battles were fought, where memorials are located, or places where early settlers lived. Still other spaces may be valued because of their benefit to the local natural environment.

Past research demonstrates that ecological benefits of preserving open space are often preferred over benefits to human consumption. Over recent decades, there has been a shift in environmental attitudes from prioritizing economic growth and human domination over nature to believing that nature is fragile and growth should be limited to protect nature (Brulle, 2008; Dunlap \& VanLiere, 1978). Consistent with this greater focus on ecological preservation, research demonstrates protecting open spaces that promote resources and wildlife health (e.g., lakes and ponds) is more highly valued than open spaces that are designed for human use (e.g., golf courses; Backlund et al., 2004).

Economic data also indicate preferences for preserving less-developed open spaces. In order to quantify the value individuals attach to open spaces, researchers typically estimate the perceived economic value of the space by asking respondents how much they would be willing to pay for preservation of an open space (Geohagen, 2002; Irwin, 2002). Researchers may also estimate the value of an open space by examining property values near the space and examining whether property values are best explained by proximity to the space. Measuring the economic value of permanently preserved open spaces has shown that proximity to permanent and less-developed open space increases private property values (Geohagen, 2002). Proximity to both agricultural and forested lands that are kept permanently undeveloped are associated with higher property values when compared to open spaces that are available for possible development (Irwin, 2002).

\section{Environmental identity}

Environmental identity represents the extent an individual's self-concept includes a connection to the natural world (Clayton \& Opotow, 2003; DevineWright \& Clayton, 2010; Schultz et al. 2004). There are several different types of 
identity. One type of identity is reflected in feeling connected to nature. Greater connection to nature is associated with greater concern about animals such as support for animal rights (Schultz \& Tabanico, 2007), protecting species in the wild, and caring for animals in zoos (Clayton et al., 2011). It is also associated with many pro-environmental attitudes and actions, such as seeking contact with preserved natural spaces, support for environmental movements and causes, recycling, and buying sustainable products (Tam, 2013).

Given these pro-environmental associations with environmental identity, connection to nature would logically be associated with a desire to preserve open space and greater importance placed on qualities afforded by preserving open space. For example, those who are more connected to nature are more likely to participate in outdoor recreation (Wolsko \& Lindberg, 2013). This association suggests that those who are more environmentally identified would perceive recreational opportunities afforded by preserving open space as more important than those who are less environmentally identified. However, the type of outdoor reaction matters (Wolsko \& Lindberg, 2013). Those who are more connected to nature are more likely to engage in activities such as walking one's dog outdoors, jogging outdoors, hiking, cross-country skiing, snowshoeing, canoeing, kayaking, and rafting. In contrast, they are less likely to engage in motorized outdoor reaction (riding an all-terrain vehicle, off-road motorcycle, or snowmobile, for example). This difference is consistent with connections to nature being associated with a desire to preserve nature. Thus, the qualities of open space that individuals most closely identified with or connected to nature would rate as most important would be those associated with preserving the open spaces, particularly for the protection of ecosystems or preventing development.

People can also be connected to specific natural locations, sometimes called place identity (Devine-Wright \& Clayton, 2010; Proshansky et al., 1983). They form emotional and cognitive bonds to a specific place, allowing that space to become a part of the person's identity (Devine-Wright \& Clayton, 2010; Stedman, 2002). This place identity has been shown to predict civic engagement against development of open, scenic spaces (Devine-Wright \& Howe, 2010) as well as general pro-environmental behavior (Scannell \& Gifford, 2010). However, when it comes to legislating land-use change, place identity does not always predict the same outcomes as connection to nature. In their survey of nearly 1,000 residents near Italian national parks, Bonaiuto et al. (2002) found that positive attitudes toward permanent nature preserves were found predominantly among residents with relatively low place identity and who lived farther away from the national parks. People who lived nearest the parks tended to be most concerned with local economic and pragmatic benefits from the spaces. 


\section{Present research}

\section{Description of the site}

The federally implemented Housing Act of 1961 combined the planning of transportation systems with the planning of recreation trails to encourage state governments to set forth specific policies for establishing park, forest, and other recreation and historic trails (16 U.S.C. $§ 1247,2011)$. Consistent with this Act, the Pennsylvania Open Space Lands Act 153 of 1996 allowed local governments to acquire land for preservation of open space (32 P.S. $§ 5001$ ). Located in rural central Pennsylvania next to a state forest, the open space present in Harris Township is predominantly agricultural land with little built development. Developed neighborhoods are small, somewhat scattered, and separated by stretches of open, privately owned farmland. Many of the farms are family owned and operated, and so the scale of the agricultural practices is predominantly small. There is a very small downtown area that is approximately six blocks long and three blocks wide with an immediately surrounding community.

In recent years, Harris Township has experienced a 4.3 percent ( $\%$ ) population increase in a county that has experienced some of the largest growth in Pennsylvania (13.4\% increase; Brown et al., 2012). In Harris Township, the population growth is visible in the conversion of farmlands to low density housing developments. As a result, the character of the development of agricultural open spaces is under consideration by the township and efforts to designate areas of permanently preserved open space have become a concern for residents and township leaders. To address local concerns about the rapidly declining availability of open space, community members formed an ad hoc open space committee with the goal to set procedures for identifying open spaces that can be preserved to benefit the local community and natural environment.

\section{Establishment of the Open Space Committee}

Preservation of open spaces depends upon community action and support. Community leaders must formulate plans and communicate those plans to community members, who in turn must be willing to support the mechanisms (e.g., increased taxes) for purchasing the land. In order to achieve the goal of purchasing and preserving open spaces in Harris Township, concerned community leaders began by forming an open space committee. Consistent with open space often being historically associated with recreation opportunities, the process started with the Parks and Recreation Advisory Committee.

A survey conducted by the Parks and Recreation Advisory Committee revealed that many residents were interested in more trails in the township and preserving open space. As a result, the Open Space Committee was established by the 
township's Board of Supervisors in the spring of 2009. The committee initially comprised 12 residents who had various degrees of experience with township governance and who represented most of the township's 23 neighborhoods. Attrition over the course of the committee's three-year existence resulted in the final committee being composed of eight residents at the time of the present study. The first and last authors of this paper were members of the Open Space Committee.

The committee was charged with studying all aspects of open space preservation, including identifying types of lands to preserve and ways to fund preservation efforts. The committee began by establishing a vision and mission statement for open space in their township. The committee reviewed local community laws and gathered information from other townships that had established mechanisms for preserving space in their communities. Under the lead of the first and last author, the Open Space Committee decided to conduct the present survey of community members to answer specific questions needed to plan an open space policy for the township. To assist with data collection, the survey was administered by students in a university course on conservation psychology.

\section{Content of survey}

With input from the Open Space Committee, the psychology class designed a survey to provide both practical and theoretical contributions to understanding why people do or do not support the preservation of open space. Practically, the survey results contributed to the efforts of the committee to learn about the extent to which their community supported the preservation of open space and understand the reasons for that support. Determining the extent to which community members supported increased taxes to acquire open spaces informed the committee's decisions regarding the mechanisms for preserving open spaces. Evaluation of the qualities of open space provided the basis for establishing what type of open space properties the township would pursue purchasing should landowners decide at some point to sell their property. Committee discussion referencing other open space plans in the area and state, the prior survey mentioned above, and personal experiences in the community resulted in seven qualities of open space to be included on the survey: (1) preserving ecosystems, (2) preventing likely development (e.g., within the next 5 years), (3) preserving historic places, (4) improving the ability for people to obtain access to open space, (5) providing recreational opportunities, (6) providing connections between different locations in the community (e.g., bike paths), and (7) following development plans laid out by the local government.

Theoretically, we predicted that stronger environmental identity, in terms of connection to nature and the township, would be associated with greater support for preserving open spaces. We predicted these associations because 
preserving open space would help protect and preserve the current state of the township and its natural surroundings and help build stronger community ties. Additionally, we predicted that both types of environmental identity would be associated with placing greater importance on the qualities afforded by open space. We predicted that those qualities most closely related to preserving ecology and the current state of the community (e.g., preservation of ecology and preventing development) would be more strongly related to environmental identity than those qualities related to facilitating human use of the space (accessibility, recreation, connectivity). Lastly, we predicted that these qualities, especially those related to preserving the ecology and current state of the community, would mediate the relation between both types of environmental identity and support for preserving open spaces.

\section{Method}

\section{Respondents}

Of 720 randomly selected households who were sent the survey, 390 (54\%) completed the survey, $237(34 \%)$ did not respond and the research team was unable to contact them, $76(11 \%)$ refused to complete the survey, and $6(1 \%)$ were unable to complete the survey because they did not speak English. The response rate from each neighborhood in the township ranged from $47 \%$ to $60 \%$.

Similar numbers of women and men responded (51\% female, $47 \%$ male, and $2 \%$ did not indicate their gender or indicated that a man and a woman completed the form together). Respondents ranged in age from 18 to 96 with a mean age of 54. The number of years each respondent had lived in the township ranged from less than 1 year to 76 years, with a mean of 19 years. With regard to home ownership, $83 \%$ owned their home whereas 15\% rented. Finally, 35\% of the households surveyed had children living at their home.

\section{Procedure}

Households were chosen by stratifying 2,028 addresses, provided by the township's manager, into 23 neighborhoods and then randomly selecting $40 \%$ of households from each neighborhood. After removing businesses and vacant lots, 720 households were mailed a packet of materials including an introductory letter from the chair of the township's Board of Supervisors and an information letter from the professor of the class involved in collecting the survey data (this paper's lead author). In order to randomize respondents within households, the survey began by asking that the household member with the next birthday complete the survey. The packet also included a consent form and a copy of the survey. 
The information letter described the various modes by which respondents could choose to complete the survey and when to expect interviewers to be arriving at their doors. Respondents had the option of: (1) completing the survey on their own and returning it to the township office, mailing it to the researcher, or handing it to the student from the Pennsylvania State University Conservation Psychology class who would come to their residence, (2) completing the survey in person with an interviewer, or (3) completing a web version of the survey. Four days after the packets were mailed, students began visiting households who had not submitted their survey either through the mail or online. If the survey was already completed or the respondent declined to complete the survey, students did not return to the residence. If the students were unable to contact residents, students returned up to eight additional times until someone either answered the door or it was determined for other reasons not to return (e.g., the residence appeared unoccupied). Of the 390 respondents who completed the survey, $38 \%$ returned it to the township, less than $1 \%$ mailed it to the research supervisor, $15 \%$ gave a completed version of the survey to the interviewer, $21 \%$ completed the survey in person with the interviewer, and $25 \%$ completed the survey online.

\section{Survey instrument}

\section{Definition of open space}

Respondents were first provided a definition of open space, as developed by the Open Space Committee. They were informed that the township considered open space as "a parcel of land that is predominantly undeveloped. The space can be public or private and can be small or large. Preservation of the space allows it to remain in its current state and enhancement of the space allows it to be adapted for common use." To understand the community's perceptions of open space, respondents were then asked to provide their own definition of open space in an open-ended question.

\section{Qualities of open space}

Next, respondents were asked to rate the importance of seven different qualities of open space on a five-point scale ( 1 = not at all important, $5=$ very important $)$. The qualities were presented in the following order: (1) Preserves Historic Places (e.g., historic events/people, historic buildings); (2) Preserves Ecosystems (e.g., protects drinking water, sensitive soils, wildlife habitats, special waterways, agricultural lands, rock or forest features); (3) Provides Accessibility (e.g., from neighborhoods to open space); (4) Provides Connectivity (e.g., from one open space to another, such as one bike path to another or to other types of open space); (5) Provides Recreation; (6) Prevents Likely Development (e.g., within 
the next 5 years); and (7) Is Consistent with Township or Regional Plans. As noted above, the qualities were chosen based on the committee's previously conducted survey and deliberation among the committee members.

Respondents also chose which three of the seven qualities they felt were the most important qualities of open space. The top-rated qualities were preserving ecosystems, preserving historic places, and preventing likely development. The one to three rankings correlated with one to five importance ratings of each of these three top-ranked qualities, $r(318)=.33, p<001, r(193)=.30, p<001$, $r(194)=.31, p<001$, respectively. We only present results for the ratings because respondents selected their top three qualities and, therefore, did not rank all qualities. This ranking procedure limited the ability to differentiate among the least important qualities. Respondents were also given the opportunity to indicate additional qualities they thought should be considered.

\section{Support for open space}

Respondents were asked whether or not they supported preserving open space. The prompt provided read, "In your opinion, should Harris Township preserve open space?" with a "Yes" or "No" response option.

\section{Willingness to pay for open space}

Next, respondents were asked whether they owned or rented their property. If they owned their own home, they were asked to indicate their preferred options for property taxes, should a tax be the means selected for purchasing open space. The different tax response options (in mills) were: 0 (no increase), 0.5, $0.7,1.0$, and 1.5 mills. To help respondents understand what these tax options would mean for both individuals and the township, each tax option (in mills) was presented with the amount of tax (in dollars) that the average property owner would pay with different tax rates (the average property value in the township was provided for comparison to their own property value), and the amount of anticipated revenue that the tax rate would provide to the township (in dollars). In addition, they were provided the options of "Don't know" and "Does not apply to me."

\section{Social-psychological variables}

There is currently no consensus on how to best measure environmental identity, but one common approach is to ask how connected the person is to nature or to particular places (Devine-Wright \& Clayton, 2010; Schultz, 2001). Following the logic of Schultz's (2001) single-item measure of "Inclusion of Nature in the Self," respondents separately rated the extent to which they felt connected to the township and to nature on 5 -point scales ( $1=$ not at all connected, $5=$ very connected). Connection to Harris Township was used to measure place identity. 
Respondents also rated their connection to animals because open spaces may provide residents with unique spaces to bond with their domesticated pets independent of their sense of connection to wildlife (e.g., walk one's dog). Because of the greater theoretical rationale for including a measure of connection to nature, we chose to use this measure over connection to animals. Connection to nature and to animals were highly correlated, $r(370)=0.60, p<0.001$, so results for both measures were similar.

\section{Demographic information}

Finally, respondents completed the demographic questions described in the Respondents section, above. They also indicated the neighborhood where they lived.

\section{Results}

\section{Conceptualizations of and support for open space}

Respondents' definitions of open space were coded to identify the different themes emphasized in the responses. Overall, the open-response definitions coincided with the definition provided by the Open Space Committee and noted on the survey. Specifically, 17\% explicitly agreed with the definition, $34 \%$ defined open space as open or undeveloped land (e.g., "a parcel of undeveloped land"), 20\% focused on nature (e.g., "Space where there is protected natural habitat"), 15\% focused on recreation (e.g., "A parcel of land that is used for recreational purposes and is developed for that use"), and 7\% focused on public use in their definitions (e.g., " a place that the town could use together"). An additional $21 \%$ gave specific examples of types of open space (e.g., "farmland," "fields, no house," "pasture land or woods - unused space") and $2 \%$ mentioned specific locations in the township. Finally, an "other" category $(8 \%)$ emerged, including general comments such as stating how open space can "benefit the community," can be "animal friendly," or the statements could not be coded. There were a few $(2 \%)$ who disagreed with some aspect of the definition, mostly in terms of preferring to exclude private land from the definition. Twenty percent of respondents left the answer blank. Statements could fall into more than one category, hence the percentages reported above add up to more than $100 \%$.

An overwhelming majority of respondents $(96 \%+/-2 \%, 95 \% \mathrm{CI})$ indicated they support the township preserving open space. ${ }^{2}$ Most respondents $(n=293$;

2 The last question on the survey was an open-ended option to leave any additional comments. Although most respondents $(70 \%)$ chose not to comment, the most frequent type of comment $(11 \%)$ favored preserving 
$75 \%$ of the sample and $91 \%$ of homeowners) answered the question asking about a tax preference value, should a conservation fund be established. Paying property taxes did not apply to renters so they were not asked to provide a tax preference value $(\mathrm{n}=69)$. An additional 28 respondents indicated that they did not know what tax option to select. Of the remaining 293 respondents, most $(73 \%, n=216)$ were in favor of some amount of tax increase in order to preserve open space (Figure 1). The most popular option was the lowest tax increase rate provided on the survey ( 0.5 mills). However, it is worth noting that $42 \%$ of respondents supported paying more than this amount.

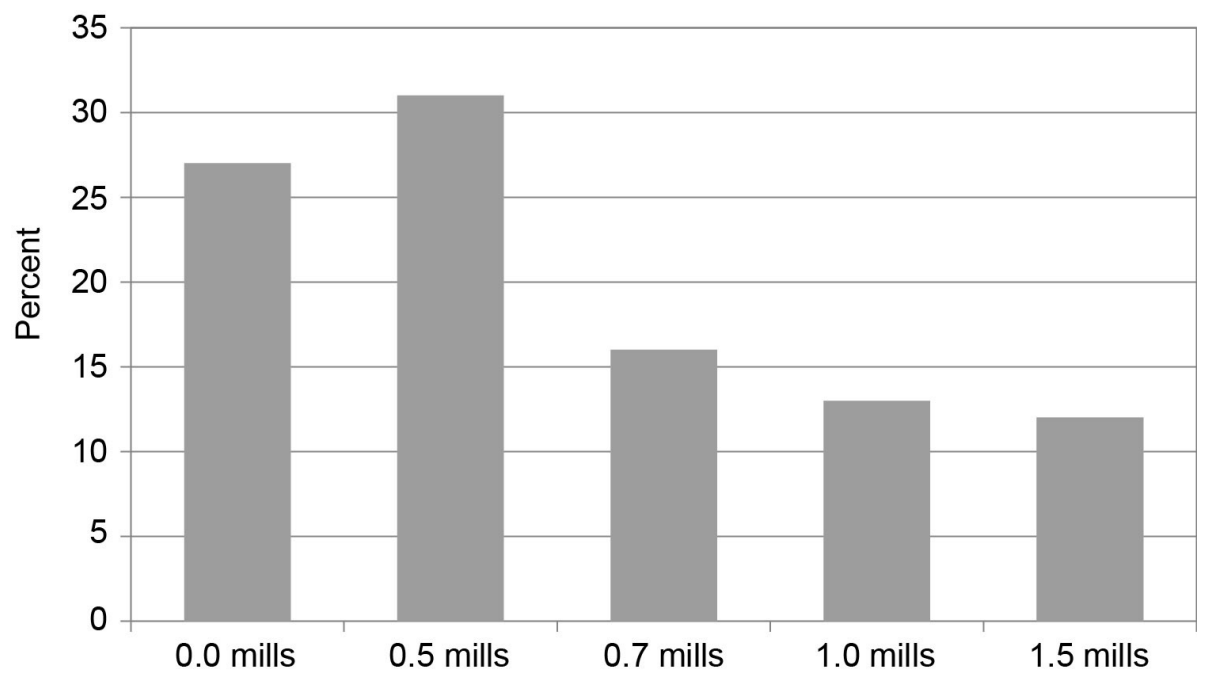

Figure 1. Percentage of respondents in favor of different tax rate increases

Note: Figure represents data only from respondents who selected a tax option $(75 \%$ of sample; $91 \%$ of homeowners).

\section{Qualities of open space}

A repeated-measures ANOVA and subsequent simple effects tests revealed that the quality of open space most valued was preserving ecosystems, followed by preventing likely development and preserving historic places, $F(6,2148)$ $=73.87, p<0.001$ (see Table 1). Respondents were given an option to list additional qualities that should be considered. The majority of respondents chose not to respond $(67 \%)$. Of those who did, most identified ideas noted in the qualities already listed, with $14 \%$ specifically elaborating on these qualities. Some $(4 \%)$ respondents made reference to other qualities not specifically mentioned in the ratings (e.g., preserving agricultural lands, education, and 
costs). Other respondents indicated they supported the development (e.g., "We need consistent development") and maintenance of open space (e.g., "Make it look nice") (5\%). The remaining comments discussed open space without any specific reference to the qualities of open space $(11 \%)$.

A principle component analysis with varimax rotation and Kaiser normalization was used to determine the underlying structure associated with the importance placed upon the different qualities afforded by preserving open space. An examination of the scree plot and Eigen values greater than one revealed a twofactor structure. The first factor accounted for $41 \%$ of the variance and reflected functional features of open space for human use (i.e., providing connectivity from one open space to another, providing accessibility from neighborhoods to open space, and providing recreation; all factor loadings for these three values $>0.76$ and factor loadings for the other four qualities $<.31$ ). The second factor accounted for $16 \%$ of the variance and reflected reasons to maintain the current state of the ecology and community (i.e., preservation of historic places, preservation of ecosystems, prevention of likely development, and consistency with township or regional plans; all factor loading values for these four qualities $>0.56$ and factor loadings for the other three qualities $<.21$ ). In order to include these measures in our mediation analyses reported below, we averaged responses to these ratings to form a measure of perceived importance of functional qualities of open space (Cronbach's $a=0.74$ ) and importance of preserving the current state of the community (Cronbach's $a=0.64$ ). Reliability for the latter measure was not improved by removing any of the four items. 
Environmental Identity and Community Support for the Preservation of Open Space

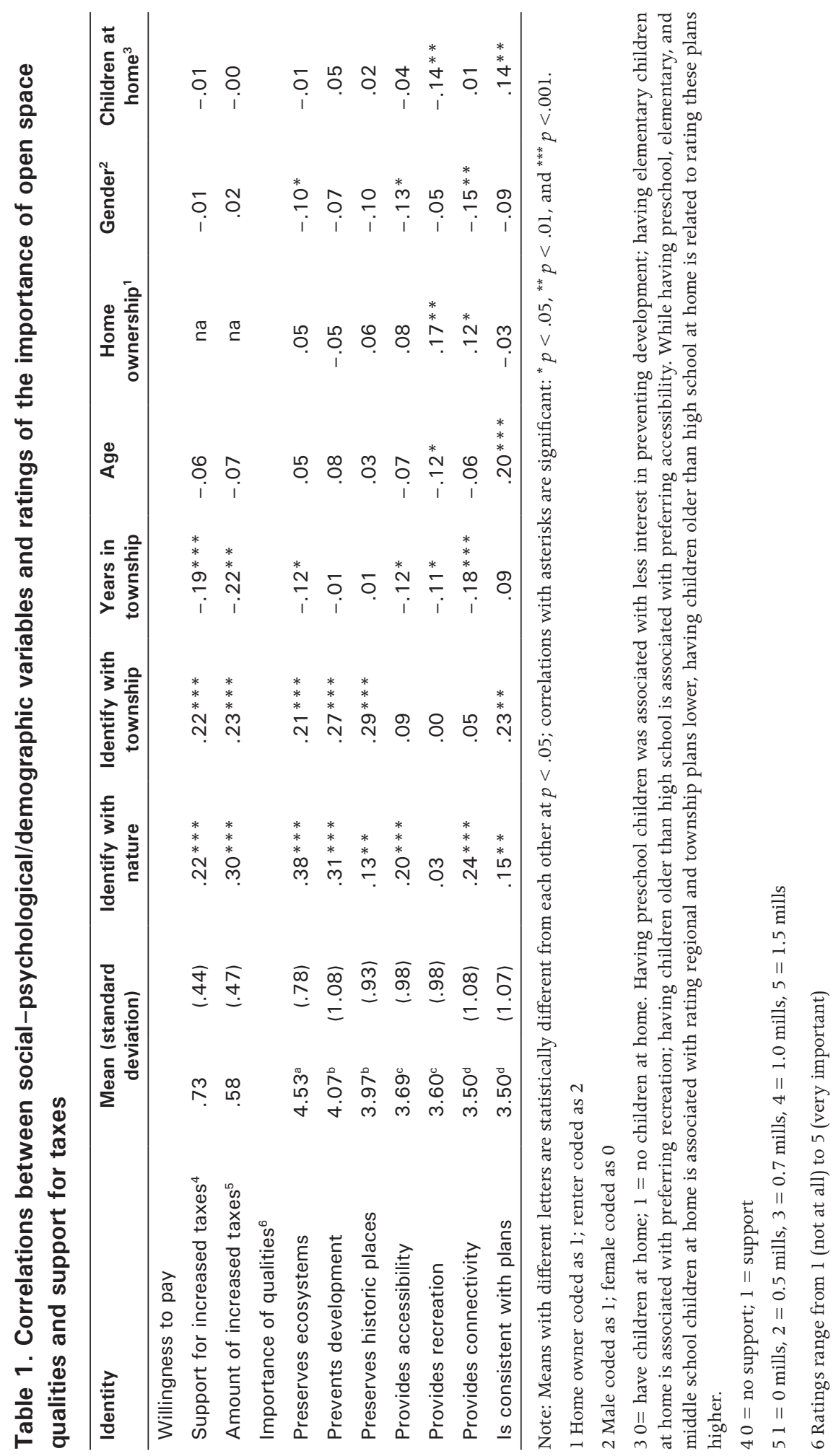




\section{Individual differences}

Consistent with predictions, stronger identification with nature (i.e., environmental identity) and the township (i.e., place identity) were associated with more support for preserving open space and the importance of most of the qualities associated with open space (Table 1). We did not examine associations with stated support for preserving open spaces because there was a ceiling effect on this variable with nearly all supporting it, as reported above. Both types of identity were associated with the qualities that reflected a desire to preserve the current state of the community. Identification with nature was also associated with providing accessibility and connectivity.

Although length of years in the township was positively correlated with connection to the township, $r(271)=.37, p<.001$, the longer residents lived in the township, the less support they had for taxes. Notably, as illustrated in Figure 2, even with the diminished support for taxes, the majority supported taxes regardless of length of residence. No other demographic characteristics were related to support for taxes. Several demographic variables, on the other hand, such as renting a home, being female, and having children living at home, predicted valuing open space for functional use (providing accessibility, recreation, and connectivity).

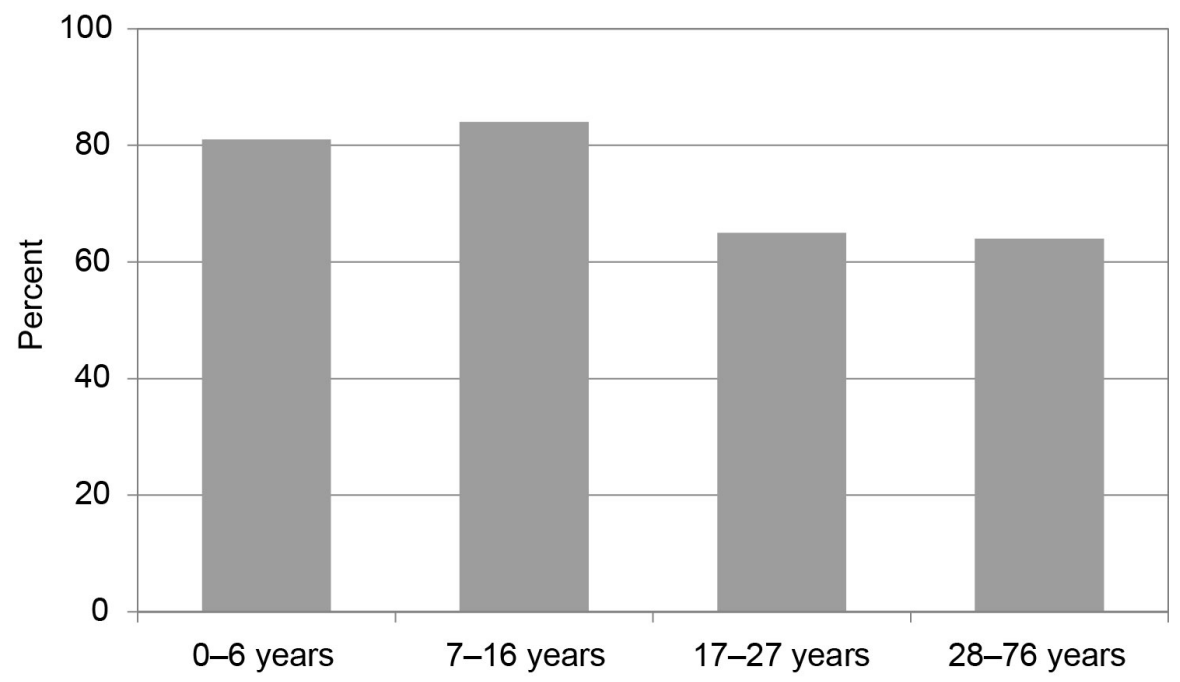

Figure 2. Percentage of respondents supporting taxes by quartile split of number of years living in the township

\section{Mediation model}

We examined whether the importance given to maintaining the current qualities of the ecology and community and the importance of functional qualities of open space mediated the relation between identification with nature and willingness 
to pay for open space and the relation between identification with the township and willingness to pay for open space. ${ }^{3}$ We tested a parallel mediation model using Hayes's (2013) PROCESS macro with 1,000 bootstraps. Parallel mediation means that we tested both mediators in the same model, which allowed us to compare the relative strength of the two mediators. We conducted separate analyses for the two predictor variables of place and environmental identity.

Rated importance of qualities that preserved the current state of the community mediated the effect of identification with nature and identification with the township on willingness to pay for open space via a property tax increase, while functional qualities did not mediate these relations (Figures 3 and 4). That is, the more connected residents were to nature and the township, the more they rated qualities that preserved the current state of the community as being important. In turn, these qualities predicted willingness to pay for open space. In contrast, although identification with nature and the township was associated with rating functional qualities as being important, in these models functional qualities were not associated with willingness to pay for open space via property taxes. Thus, the relation between environmental and place identity and greater willingness to pay for open spaces can be explained by the greater importance identified individuals placed on maintaining the current state of the community.

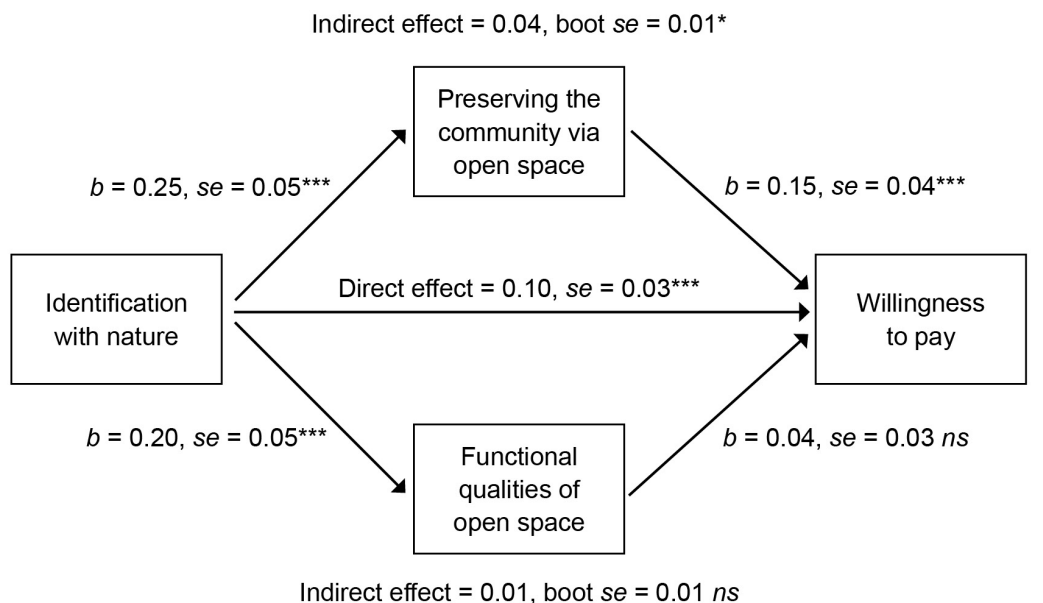

\section{Figure 3. Mediation tests of the relation between identification with nature and willingness to pay taxes for open space}

Note: ${ }^{*} p<0.05,{ }^{* * *} p<0.001$

\footnotetext{
3 We used the two measures created from the factor analyses on rated importance of qualities associated with preserving open space rather than the seven separate qualities because collinearity between importance ratings could interfere with our ability to identify the strongest mediators.
} 


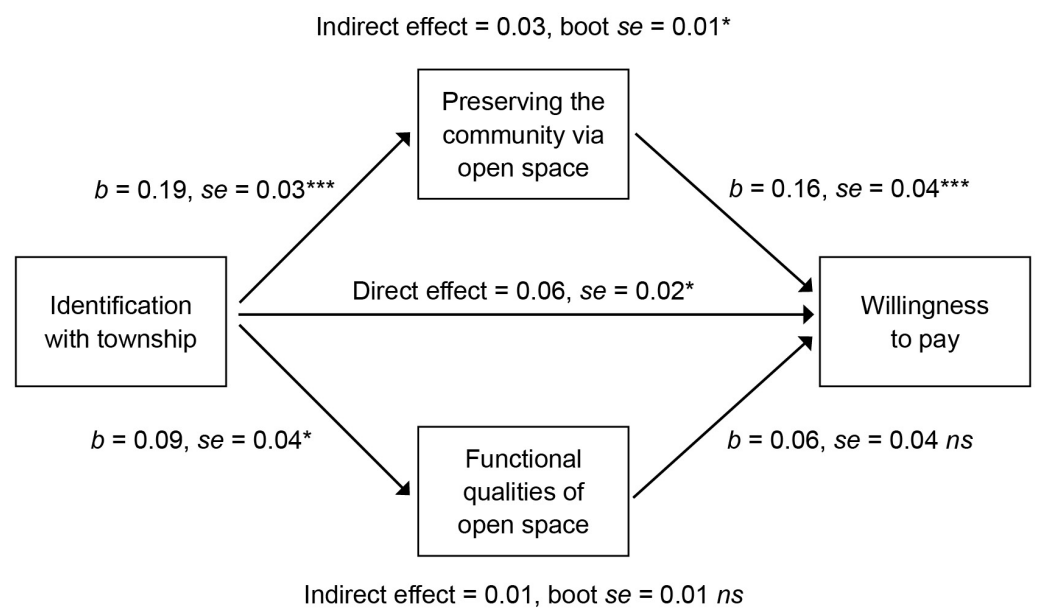

Figure 4. Mediation tests of the relation between identification with the township and willingness to pay taxes for open space

Note: ${ }^{*} p<0.05 ;{ }^{* * *} p<0.001$

\section{Discussion}

With near unanimity, residents supported preserving open space in their local community. The majority were willing to back this support by an increase in taxes. Residents rated all the qualities afforded by preserving open space as being important. The top three qualities were all related to preservation: preserving ecology, preserving historic places, and preventing development. The other qualities could be understood as ways to facilitate human use of open spaces (recreation, accessibility, connectivity, and following township plans). The prioritization could reflect the increased cultural concern for preserving and caring for the environment over utilization of the environment (Brulle, 2008; Dunlap \& VanLiere, 1978). However, preserving historic places is not directly about preserving the environment. Further, factor analyses indicated that the least valued attribute, following township plans, was more strongly associated with the three types of preservation. In contrast then, these preferences may have reflected a status quo bias rooted in loss aversion - a preference to minimize losses over acquiring gains (Kahneman et al., 1982; Kahneman \& Tversky, 1984; Samuelson \& Zeckhauser, 1988).

As predicted, the more residents identified with nature (i.e., environmental identity) and their township (i.e., place identity), the more they were willing to pay more for preserving open space. This is consistent with other research that 
indicates that communities who are generally more ecologically concerned tend to cite the environment as a strong reason for supporting policies that preserve open spaces (Banzahf et al., 2010). These two types of identity were also related to being more likely to perceive qualities afforded by preserving open space as important, especially those qualities related to preserving the current state of the community. However, identification with nature was also related to the perceived importance of increased accessibility to open spaces from, for instance, neighborhoods, and better connectivity to open spaces such as via bike paths. This may be because greater connection with nature is associated with participating in outdoor activities, such as hiking (Wolsko \& Lindberg, 2013). Mediation analyses indicated that greater identification with nature and the township was related to support for preserving open space because these types of identification are associated with valuing the qualities that allow the community to preserve its current state over qualities that increase the functional use of the space.

Only one demographic characteristic was associated with support for preserving open space. One might expect that length of residency would result in greater support for open space because those with longer residency have more connections to the community and associations with place identity. However, those who lived in the township longer were less supportive of property taxes. The negative relation with residency could be a function of longer time residents being older, $r(359)=.26, p<.001$. Older residents are more likely to be on fixed incomes, which could make property taxes more of a burden for them. This difficulty was mentioned by several people in open-ended comments to the survey. However, age was not associated with support for property taxes. Alternatively, the negative relation could be a function of differences in political persuasion; longer time residents may have been more politically conservative and less supportive of taxes in general. Yet it is important to note that even among long-term residents (i.e., living in the community for more than 27 years) more people supported taxes than did not (see Figure 2).

\section{Utilization of survey results by the Open Space Committee}

The results of the survey were presented to the township's Board of Supervisors and the community through various methods of communication. The presentation to the Board of Supervisors was also open to the community. Further, community members were invited to attend a meeting in the local community building to learn about the activities of the Open Space Committee, including the survey results. Several neighborhood meetings were also held to go over the work done by the committee. 
Echoing the voice of the vast majority of survey respondents (96\%), the committee confidently recommended that the township's Board of Supervisors support the preservation of open space. The committee also recommended an income tax increase to fund the preservation of open space. Results from the survey suggested that a large majority of homeowners $(67 \%)$ were willing to pay increased property taxes to help fund the preservation of open space. At the same time, a few home owners - particularly those with fixed incomes - were strongly opposed to increased taxes. As a result, the Open Space Committee recommended an increase in income tax rather than property tax, an option the committee was unaware was legally possible at the time of the construction of the survey.

In addition, the results of the survey informed the specific content of the open space policy developed by the committee. For example, respondents tended to rate qualities that reflected ecological reasons (preserving ecosystems and preventing likely development) and maintenance of the character of the area (e.g., historic places) as important to very important, and they tended to rate qualities that reflected the functional use of open space (accessibility, recreation, and connectivity) as moderately important to important. These ratings were usedaccording to the open space policy - to evaluate and weight the desirability of property, should it become available to the township for purchase.

An interesting unintended consequence of conducting the survey was that it raised awareness among residents about the Open Space Committee's activities, furthering citizen participation. The survey results became a discussion among other township committees. There were also reports of discussions about the survey and open space among residents' informal conversations. Thus, the survey itself was not only a central part of the planning process but it became an educational and agenda-setting tool as well. Community surveys could serve as an important tool for getting specific issues on the political agenda within a community.

\section{Limitations}

The survey is limited in its ability to fully account for willingness to support preservation of open space. Not only was the survey intended to be relatively short (fitting on one page of paper) for the convenience of respondents, the committee also decided to not ask questions that would have been useful to more fully understand support, and potentially rule out, factors confounding with identity. For instance, the committee decided to exclude questions about income, political persuasion, and tendency to vote in elections.

There are both strengths and weaknesses of two of the authors' adopting dual roles of researcher and member of the Open Space Committee. The presence of 
the authors on the committee allowed them to fully understand the discussions and needs of the committee and have these discussions and needs reflected in the content of the survey and to be able to interpret the results in a manner that was most useful for the committee. On the other hand, concerns might be raised about the authors' ability to remain objective in their two roles as committee member and researcher. Yet, concerns about objectivity are allayed for at least two reasons. First, the authors were not evaluating the committee's performance but instead providing information to the committee about the township. Second, objectivity was aided by the full committee having input in the construction of the survey and the township's Board of Supervisors reviewing and approving the survey prior to its administration.

The survey results were not predictive of the township's vote on a referendum to raise funds for preserving open space through raising income tax by $0.6 \%$. The referendum was narrowly defeated with less than a $1 \%$ difference between those in favor and those against it. There are a number of possible reasons for the defeat. There could be factors associated with the survey. Because the committee decided to exclude a question asking about voting tendencies, the survey was limited in its ability to identify preferences for the subsection of the community that would likely vote. Thus, the survey may have indicated the township preferences but not represented the voters' preferences. A mismatch in the information in the survey and that on the ballot may have been important. The survey clearly defined open space and the ratings could have made reasons for support for open space salient. Neither of these types of information was present on the ballot. The committee went through much effort to educate the community about the referendum via community meetings, flyers, and information on the township's web page. Yet, these took some effort on the part of the community to attend to this information. The mismatch in information between the survey and the ballot means that other factors could have influenced the vote that did not influence responses on the survey. Ironically, a status quo bias could have influenced voters to not support the referendum. This is ironic because it is possible that a status quo bias may have been the reason why survey respondents supported qualities of open space that would preserve the current nature of the township. Another possible factor was misinformation. Oppositional signs were posted throughout the township the day before the election which did not give the committee time to address the misinformation on the signs. Perhaps the most likely alternative factor influencing the vote was that the vote occurred during a contested national election where there was much discussion about "no new taxes." This national tone may have influenced sufficient number of voters to reject the referendum because of the greater salience of political over ecological principles. 


\section{Conclusion}

In response to local government leaders noting changing demographic and land use and a previous survey revealing citizens' desire for more trails and preserving space, community leaders and concerned citizens volunteered for an ad hoc committee to formulate recommendations for preserving open space in their communities. The survey assessed community perceptions of and support for preserving open space, as well as investigated the role of place identity in support for preservation of open space and increased taxes as a mechanism of support therefor. The survey gave voice to the citizens of Harris Township and increased citizen participation in their local government.

Residents of the township showed a strong endorsement of the protection of ecosystems consistent with historical trends toward viewing the need to protect the environment from human infringement. The survey also validated the role of identity in understanding support for open space, a type of proenvironmental action. Attention to identity revealed a source of variation in support for property taxes dedicated to preserving open space. Those who were more connected to nature in general, and more connected to the township in particular, were more supportive of increased taxes. Both of these relations were mediated by the importance residents placed on maintaining current status of their community and community plans.

The survey results continue to contribute to the township, providing the basis for continued exploration of how to achieve open space preservation in the township. Theoretically, this study offered insight into the role of place identity and connection to nature as predictors of willingness to pay for open space, as well as some of the underlying psychological mechanisms that may be involved in community participation in preventing environmental development and degradation. Lastly, in addition to providing the results and an opportunity for the inclusion of the community voice in township decision-making, the discussions about the survey itself may have contributed to increasing community awareness about issues surrounding the preservation of open space and the natural environment more generally.

\section{Acknowledgments}

Portions of this paper were presented in a white paper for Harris Township, Pennsylvania, and are reported in Harris Township's official Open Space Plan and the American Psychological Conference 2011 convention in Washington DC. We would like to thank Amy Farkas (the township manager) and the Harris Township staff for their assistance in conducting the survey. We would also 
like to thank the members of a Pennsylvania State University Conservation Psychology class for their assistance on this project. These class members were: Katherine Angulo, Meghan Bisbey, Kara Brehm, Ross Carpenter, Efrain Castillo, Erica Cherry, Kathleen Childs, Mathew Clark, Julia Cutler, Lindsey Epley, Kristi Falco, Rebecca Gibson, Amanda Gingrich, Caitlin Gregory, Rebecca Hartman, Justin Hughes, Maryana Kagalovskaya, Jacqueline Kralik, Sarah Kretz, A-Rim Lee, Briana Lieberman, Michelle Mancini, Madeline Martinez, Feryne McSweeny, Amanda Migliaccio, Michalyn Millen, Eun Jung Moon, Stephanie Myers, Rachel Peck, Cory Peterson, Alyssa Pettinato, Stephanie Pratt, Michelle Rapp, Ansimon Rezk, Amey Rosati, Kathleen Wagner, Rebecca Ware, Edward Wickland, and Courtney Williams.

\section{References}

Backlund, E. A., Stewart, W. P., \& McDonald, C. (2004). Public evaluation of open space in Illinois: Citizen support for natural area acquisition. Environmental Management, 34(5), 634-641.

Banzhaf, S. H., Oates, W. E., \& Sanchirico, J. N. (2010). Success and design of local referenda for land conservation. Journal of Policy Analysis and Management, 29, 169-179. doi: 10.1002/pam

Bonaiuto, M., Carrus, G., Martorella, H., \& Bonnes, M. (2002). Local identity processes and environmental attitudes in land use changes: The case of natural protected areas. Journal of Economic Psychology, 23, 631-653.

Brown, E., DeBarros, A., Deramus, K., Greeneltch, C., Miller, R., Overber, P., ... Thomassie, J. (2012). Census. USA Today. Retrieved from http://www. usatoday.com/news/nation/census/profile/PA

Brulle, R. J. (2008). The U.S. Environmental Movement. In K. Gould \& T. Lewis (eds.), 20 Lessons in Environmental Sociology (pp. 14-18). New York: Oxford University Press.

Clayton, S., Fraser, J., \& Burgess, C. (2011). The role of zoos in fostering environmental identity. Ecopsychology, 3, 87-96. doi: http://dx.doi. org/10.1089/eco.2010.0079

Clayton, S., \& Opotow, S. (2003). Introduction. In S. Clayton \& S. Opotow (Eds.), Identity and the natural environment (pp. 1-24). Cambridge, MA: MIT.

Cordell, H. K., Bergstrom, J. C., Hartmann, L. A., \& English, D. B. K. (1990). An analysis of the outdoor recreation and wilderness situation in the United States, 1989-2040. Gen. Tech. Rep. RM-GTR-189. Fort Collins, CO: U.S. Department of Agriculture, Forest Service, Rocky Mountain Forest and Range Experiment Station. 
Devine-Wright, P., \& Clayton, S. (2010). Introduction to the special issue: Place, identity and environmental behavior. Journal of Environmental Psychology, $38,267-270$.

Devine-Wright, P., \& Howe, Y. (2010). Disruption to place attachment and the protection of restorative environments: A wind energy case study. Journal of Environmental Psychology, 30, 271-280.

Dunlap, R. E., \& VanLiere, K. D. (1978). The "new environmental paradigm": A proposed measuring instrument and preliminary results. Journal of Environmental Education, 9(1), 10-19.

Geoghagen, J. (2002). The value of open spaces in residential land use. Land Use Policy, 19, 91-98.

Hayes, A. F. (2013). An introduction to mediation, moderation, and conditional process analysis. New York: Guilford Press.

Irwin, E. G. (2002). The effects of open space on residential property values. Land Economics, 78(4), 465-480.

Jensen, C. R., \& Guthrie, S. P. (2006). Outdoor recreation in America. Champaign, IL: Human Kinetics.

Kahneman, D., Slovic, P., \& Tversky, A., (1982). Judgment under uncertainty: Heuristics and biases. Cambridge, UK: Cambridge University Press.

Kahneman, D., \& Tversky, A. (1984). Choices, values, and frames. American Psychologist, 39(4), 341-350.

Kline, J. D. (2006). Public demand for preserving local open space. Society \& Natural Resources, 19, 645-659.

McDonald, R. I., Forman, R. T. T., \& Kareiva, P. (2010). Open space loss and land inequality in United States' cities, 1990-2000. PLOS ONE, 5(3), e9509. doi: 10.1371/journal.pone.0009509

Moore, R. L., \& Driver, B. L. (2005). Introduction to outdoor recreation. State College, PA: Venture Publishing.

Proshansky, H. M., Fabian, A. K., \& Kaminoff, R. (1983). Place-identity: Physical world socialization of the self. Journal of Environmental Psychology, 3, 57-83. doi: 10.1016/S0272-4944(83)80021-8

Samuelson, W., \& Zeckhauser, R. (1988). Status quo bias in decision making. Journal of Risk and Uncertainty, 1(1), 7-59.

Scannell, L., \& Gifford, R. (2010). The relations between natural and civic place attachment and pro-environmental behavior. Journal of Environmental Psychology, 38, 289-297.

Schultz, P. W. (2001). Assessing the structure of environmental concern: Concern for self, other people and the biosphere. Journal of Environmental Psychology, $21,1-13$. 
Schultz, P. W., Shriver, C., Tabanico, J., \& Khazian, A. (2004). Implicit connections with nature. Journal of Environmental Psychology, 24, 31-42.

Schultz, P. W., \& Tabanico, J. (2007). Self, identity, and the natural environment. Journal of Applied Social Psychology, 37, 1219-1247.

Stedman, R. C. (2002). Toward a social psychology of place predicting behavior from place-based cognitions, attitude, and identity. Environment and Behavior, 34(5), 561-581.

Tam, K. P. (2013). Concepts and measures related to connection to nature: Similarities and differences. Journal of Environmental Psychology, 34, 64-78.

USDA (United States Department of Agriculture). (2006). Cooperating across boundaries: Partnership to conserve open space in rural America. Forest Service FS-861. Retrieved from http://www.fs.fed.us/openspace/ cooperatingacrossboundaries.pdf

Wolsko, C., \& Lindberg, K. (2013). Experiencing connection with nature: The matrix of psychological well-being, mindfulness, and outdoor recreation. Ecopsychology, 5(2), 80-91. 
This text taken from Human Ecology Review Volume 20, Number 2, 2014, published 2014 by ANU Press, The Australian National University, Canberra, Australia. 